\title{
Outdoor lighting design as a tool for tourist development: the case of Valladolid.
}

For submission to European Planning Studies

\author{
Emanuele Giordano*
}

ART-Dev UMR 5281, Université Paul Valéry Montpellier III, Site SaintCharles, Route de Mende, cedex 5, 34199 Montpellier, France

Tél./Fax : +33411757107

ema.giordy@gmail.com

*Corresponding author

The Version of Record of this manuscript has been published and is available in European Planning Studies, Published online: 13 Aug 2017, http://www.tandfonline.com/doi/full/10.1080/09654313.2017.1368457 


\title{
Outdoor lighting design as a tool for tourism development. The case of Valladolid.
}

\begin{abstract}
Practices of outdoor illumination have dramatically changed in the last decades as functional lighting has progressively given way to a more qualitative vision of light. Its traditional role for security purposes has been progressively matched by the use of illumination for city beautification. This is now a major consideration for new lighting strategies. As a result, a growing number of European cities explicitly include the development of nocturnal tourism among the objectives of their lighting policies. However, little attention has been paid by academic research to this growing trend. Focusing on the internationally renowned lighting project "Ruta de los Rios de Luz" this research paper explores the use of lighting design for tourism purposes. Through interviews with individuals who played an important role in the project, the discussion below scrutinizes the lighting design decisions and the economic, environmental and political objectives that inspire the growing utilization of spectacular forms of illumination for tourism purposes.
\end{abstract}

Keywords: illumination, nightscape, tourism, urban design.

\section{Introduction}

The practices and policies related to urban illumination have changed dramatically in the last decade. Under pressure from several different factors - cuts to their budget (Peck, 2012), technological developments (Meier, Hasenöhrl, Krause \& Pottharst, 2015) and the demands of climate-change mitigation (Bulkeley, Broto \& Edwards, 2012) - local authorities are looking towards changes in their lighting strategies in order to reduce their financial burden and energy consumption (Shaw, 2014). At the same time a growing awareness that artificial light is not purely benign has emerged in research and policy. As a consequence, new forms of lighting regulation designed to reduce light pollution are becoming increasingly common at local and even national levels. For example, Slovenia passed legislation on the subject in 2007, with France following in 2013 (Meier et al., 2015). However, lighting design has also followed another path of development. A more theatrical deployment of light has emerged in the contemporary cultural economy and new modes of illumination are increasingly employed to enhance the urban night-time experience (Ebbensgaard, 2015a; Edensor, 2015b; Edensor and Lorimer, 2015). Initially limited to temporary events, this new approach to urban design is no longer confined to controlled environments but is becoming a distinctive feature of the contemporary city, increasingly affecting everyday illumination. This has led to a dramatic change in the scale, scope and policies of urban lighting strategies, resulting in an 
increase in the sphere of intervention and the application related to urban illumination (Köhler, 2015). The traditional security purpose has been progressively matched by the use of light for city beautification which is becoming a major concern of urban lighting strategies (Van Santen, 2006). As a result, an increasing number of municipalities have started to consider urban illumination as a potential tool of urban development (Alves, 2007; Meier et al., 2015). This aspiration is mainly motivated by the idea that new spectacular forms of illumination provide an opportunity to attract visitors and tourists, leading a growing number of cities to explicitly include the development of nocturnal tourism among the objectives of their lighting policies and strategies (Deleuil, 2009; Guo, Lin, Meng \& Zhao, 2011).

However, little attention has been paid by academic research to this growing trend. This paper therefore presents the case of the internationally renowned "Ruta de los Rios de Luz" lighting project, developed in 2011 by the Spanish city of Valladolid in order to scrutinizes the rationale beyond the lighting design decisions and the way in which both lighting designers and local authorities conceptualize the use of illumination for tourism purposes. This reveals more about how and why lighting projects are being designed to achieve a diverse range of economic, environmental and political objectives.

The paper begins by tracing the growing importance of urban design within the contemporary city and its relationship with urban tourism (Gospodini, 2001). After tracing the way in which the role of illumination has changed from being a functional and pragmatic component of a cityscape to becoming a theatrical device essential for staging an exciting urban experience for residents and tourists, the discussion turns to the case study and conclusions.

\section{Urban design and tourism}

In discussing how European cities are changing, many authors have emphasized the growing importance that urban design is assuming in the contemporary city and how the production of visually and spatially coherent urban buildings and spaces appears to be increasingly central to urban change (Gospodini, 2002; Julier, 2005; Madanipour, 2006). In the context of a constantly growing inter-urban competition and a desire for increased recognition, visibility and tourist flows, many local authorities have perceived urban design as a favoured approach to re-orchestrate place identity through staging new specific aesthetic outlooks for the city. Through investing in architecture, landscaping and design, cities claim the possession of various cultural values and try to enhance their status in an increasingly competitive context. 
While this shift is not entirely due to the growing importance of tourism in the contemporary city, but rather the result of a complex interconnection between different economic, political and cultural conditions, the fact that tourism has emerged in recent decades as one of the strategic sectors in the portfolio of urban economies is a central element in this process (Dicks, 2003; Gospodini, 2001; 2004; Jönsson, 2011). For instance, the construction of new iconic buildings characterized by innovative design, and often built to host cultural facilities, is a strategy developed by a growing number of cities wishing to improve their image and attract tourist flows (Plaza, 2000; Smith and von Krogh Strand, 2011; Stephenson, 2014). The most frequently cited example of a building designed to influence wider development and city image is the Guggenheim Museum in Bilbao whose success has some authors talking of a "Guggenheim effect" (Plaza, Tironi \& Haarich, 2009; Plaza \& Haarich, 2015). As suggested by McNeill (2000), city marketing and tourist development were dominant reasons for its creation and given these criteria, the museum seems to have been successful. For example Plaza (2000) estimates that from October 1997 to July 1999 the Bilbao Guggenheim accounted for 58 percent of the increase in tourism to the Basque Country. However, while this model has been serially replicated by numerous European cities, other researches have expressed doubts about the effectiveness of strategies based on the simple construction of new iconic buildings. Ockman (2004) for instance argues that Bilbao's success was not dependent solely on the Guggenheim but was instead the result of a more extended regeneration programme. In a similar vein, Beriatos and Gospodini (2004) criticise the "scattered model of regeneration" (p. 194) chosen for the 2004 Athens Olympics, arguing that the simple construction of new buildings without concern for the surrounding environment was unable to enhance the perception of the city's landscape. As a result, this new aesthetic concern does not take shape through the sole creation of new urban landmarks. A wide range of softer, though less pervasive, actions are developed to improve the formal qualities of the city space. Alongside the construction of new cultural flagships, a series of measures have been implemented to "dress up" the urban environment: new paving, themed decor elements, designed street furniture and tourist signage are increasingly used to produce new urban designscapes (Julier, 2005). Accordingly, Gravari Barbas (1998) speaks of the emergence of a new aesthetic of the city, a process that helps to transform the contemporary Western city into an adventure playground for tourism and leisure. For Gospodini (2001) this trend is motivated by the possibility of appealing to a wider audience due to the fact that "the morphological and not the functional dimension of space is in this case used as the pole of visitor's attraction" (p.291). 
Yet this process of aesthetization should not be simply understood as a series of cosmetic actions that aim to make the city more attractive. Instead, it reveals an attempt to actively shape the visitors' performances and perceptions (Edensor, 2001). The goal is "to give a city a certain readability, making it more accessible, especially to a non-local public" (GravariBarbas, 1998 p. 178). As a result, the contemporary city is increasingly projected and presented to visitors through the establishment of a "unifying and immutable idea throughout its space" (Lukas, 2007 p. 2). Thematic and design codes have become a tool to give the city a more coherent visual narrative supporting what Julier calls "the wholesale aesthetic orchestration of systems" (2005, p. 875) that coherently organizes signs, images and meanings across the urban space. The aim is to produce an aesthetic framework that makes the city easier to interpret, more legible and visitable. Designed for a short stay, the city should allow for quick consumption and immediately show its best assets to tourists, avoiding any confusion and complexity. As Dicks stresses "identity is expected to be easily accessed by those visitors or, to use a currently favoured term in urban design, to be legible. Places, whose identity seems inaccessible, confusing or contradictory do not present themselves as destinations" (Dicks, 2003 p. 1).

According to Freitag, this attempt to "create and control a cultural as well as a physical environment" (1994, p.541) has led to the production of a city of surfaces, calculated to offer a monitored visual effect, encoded with clear visual codes and signs. Through what has been defined as urban scenography (Gottdiener, 1997 p.73), city planners are attempting to direct the tourist gaze and actions towards particular attractions and features and away from "extraneous chaotic elements", reducing "visual and functional forms to a few key images" (Rojek, 1995 p.62). For instance Van der Hoeven, Smit and Van der Spek (2008) reveal how in different European cities urban design is increasingly used to reduce the complexity of the urban landscape, producing a cityscape easier for tourists to interpret and navigate. Drawing on a wide range of cases, they examine how city planners increasingly utilize different design codes to channel visitors into networks of thematic pedestrian routes that could offer a meaningful, yet highly supervised, experience of the city. Due to the spread of this phenomenon at a global level, various reports have explored the modalities through which this "global urban design formula" (Stevens and Dovey, 2004 p. 354) is applied in a wide array of geographical and spatial settings (Gospodini, 2002). However, following a broader tendency in academic research, these reports have focused on the cityscape by day while the effects of this shift on the nocturnal landscape have been overlooked. 


\section{The changing landscapes of illumination}

For most of the second half of the 20th century, outdoor illumination has been treated as a purely operational and technical matter whose unique function was to guarantee the operation of the urban factory during the night (Deleuil and Toussaint, 2000). However in the past few years, things have begun to change significantly with the confluence of political and technological developments deeply affecting lighting itself as well as the way it is conceived (Deleuil, 2009; Meier et al., 2015).

In the context of austerity policies characterized by constant cuts to their budget and the increasing demands of climate-change mitigation, local authorities are under a growing pressure to develop new low-carbon forms of energy use (Bulkeley et al, 2012). In this new political climate, outdoor illumination has received special attention as it is one of the larger sources of electricity consumption and one of the areas in which the greatest level of autonomy and flexibility remains (Shaw, 2014).

Yet the growing concerns related to outdoor illumination are based on more than economic and energy considerations (Deleuil, 2009). Over the last few years, an increasing awareness has emerged about the negative impacts that excessive illumination has on the environment and human health, and artificial light is nowadays considered as a potential source of environmental contamination (Brons et al., 2008; Challéat, 2010). Due to the fact that many species in both terrestrial and aquatic ecosystems use the level of ambient light to regulate their metabolism, growth and behaviour, ecological light pollution produces disorientation and impacts these natural cycles, even disrupting the behaviour of organisms many kilometres away from light sources (Longcore and Rich, 2004).

Finally, criticisms related to excessive illumination have emerged in relation to more aesthetic concerns. Light pollution obscures nighttime stars and reduces the aesthetic potentialities of light, with a growing number of public campaigns being aimed at protecting the dark sky (Rodrigues et al., 2015; Edensor, 2015a). Under pressure from these different contexts, an increasing number of local authorities are looking towards changes as to how they can light their districts. Usually, this entails the progressive substitution of traditional high-pressure sodium (SON) lighting with new LED lighting. According to Shaw (2014) this technological transition offers several benefits. LED technology requires lower levels of energy to create the same level of illumination as traditional technologies, they have an extended life cycle and they produce less light pollution as they can be switched on and off much quicker whilst consuming less energy. However, while technological innovation could 
potentially improve the efficiency of energy costly systems, it does not necessarily reduce the overall energy consumption or environmental impact. Despite the fact that the luminous efficiency doubled in the UK between 1950 and 2000, per capita electricity consumption for lighting increased fourfold (Fouquet, 2006).

Accordingly to Kyba, Hänel and Hölker (2014) this "rebound effect" has historically been caused by a lack of attention to the spatial distribution of lighting sources. Traditionally, the illumination of urban space has been an ongoing, largely contingent and improvisational process. The result has been the overlapping of different, non-coordinated ad hoc operations that have largely contributed to the over-illumination of the urban space. As Köhler (2015) points out, "the situation in the illuminated space quickly reveals the visually competitive outcome - something that leads directly to wasteful energy expenditure due to the overlay of the functional and artistic application of light".

However this situation has started to change in the last decade, with a growing awareness of lighting design emerging in municipal planning practices. Many cities have adopted new planning instruments in order to rationalize the number and distribution of existing light sources while at the same time developing a long-term strategy for future operations (Deleuil, 2009). The adoption of these instruments certainly reflects the growing environmental and economic concerns related to urban illumination, though it is also associated with the growing interest in the beneficial characteristics of light (Ebbensgaard, 2015b). Cities and towns are rediscovering potential dimensions of urban lighting that go well beyond its nature as a technical matter. Its traditional security role has been progressively matched by new ones and nowadays the use of urban illumination for city beautification seems to be a major concern for new lighting strategies (Van Santen, 2006; Schulte-Römer, 2011). As noted by Meier, Pottharst, Krause and Hasenöhrl, currently "the possibilities artificial illumination offers to open up new perspectives on the night-time city that are markedly different from daytime perceptions are purposefully put to use in the context of urban renewal, place making and city marketing" (2015, p. 2). As a result, a growing number of cities are developing innovative forms of architectural illumination to enhance the aesthetical appearance of the urban landscape and generate new visual experiences and affective atmospheres.

However, the effectiveness of these innovative forms of illumination largely depends on the possibility to contrast against a dark backdrop. As some academic reports have recently pointed out, light and darkness rather than opposite realities should be understood as complementary elements, where sensory and aesthetic qualities largely depend on the copresence and transition from one condition to the other (Morris, 2011; Edensor, 2015a). Such 
perspectives have also been adopted by local authorities and designers resulting "in redirecting light-planning policies so that night and darkness may be found anew. Far from being a step backwards in the need for light, it reaffirms the symbolic power underlying the use of light. Nowadays, we have realized that light only puts on a show if it breaks out of darkness" (Alves, 2007 p. 1254). As noted by Roger Narboni, a leading figure in lighting design from both a professional and theoretical perspective (Narboni, 2004; 2012), "lighting design has evolved from an architectural lighting approach to a more holistic approach including the landscape, urban forms and nocturnal ambience for pedestrians living there or wandering around" (LUCI, 2015 p.17).

Innovative and spectacular forms of illumination are designed into the framework of a lighting concept for the whole city, often formalized into new planning instruments like the Lighting Master Plan. Light is increasingly designed as a sort of scenic material that could be used to enhance the visual appearance of the city and generate a greater sense of navigation at night and a greater appreciation of the elements of the city highlighted and facilitated via the spectacle of calculated illumination. As Alves (2007) points out, "light may give a space, which has been broken up by disorderly urban growth, physical coherency" and "helps to identify urban structure and increase the speed and the capacity needed to control or get to know a given territory" (p.1255). In a similar vein according to Ebbensgaard (2015a), "illumination is neither to be understood as mere lighting design nor as light art practice, but rather lighting that aims at beautifying and improving the liveability of urban spaces" (p. 1). This shift is reflected by a new vocabulary of light. Expressions such as "staging of light", or "light-scenography" are commonly employed, with some light designers even speaking of theatralization (Fiori, 2000; Mallet, 2010). Yet despite the fact that permanent forms of illumination have become key features of place promotion and regeneration strategies (Edensor and Millington, 2012), they have received until now relatively little attention. Existing studies have mainly focused on temporary lighting events (Edensor, 2012; Edensor, 2015b, Edensor and Lorimer, 2015) or on street lighting (Shaw, 2014; Meier et al, 2015; Deleuil, 2009).

\section{Research Methods}

In recent years urban lighting has emerged as an interesting area of research. However until now studies on urban illumination have mainly dealt with the sensory every-night 
experiences of illuminated spaces (Edensor, 2012; Edensor, 2015b, Edensor and Lorimer, 2015; Ebbensgaard, 2015a). With the exception of Shaw (2014), researchers have rarely questioned the way in which light designers and engineers or local authorities conceptualize the use of illumination and its goals. As such, this paper aims to scrutinizes the lighting design decisions and so contribute to the current debate on urban illumination offering a new insight into the wide array of economic, environmental and political objectives that inspire the growing use of spectacular forms of illumination for tourism purposes.

The project "Ruta de los Rios de Luz" is of particular interest due to its status as a national and international benchmark. Since its creation the project has won several national and international lighting design awards, including the city.people.light prize awarded by LUCI association and Philips in 2012, and has been presented as best practice in both professional and institutional publications (ATOUT, 2012). As such, the case of Valladolid is an interesting opportunity to analyse a project that offers an exemplary overview of the current lighting design trends. This is achieved via both secondary and primary sources. The secondary sources focus on the official documents that concern both the lighting project and Valladolid's tourist development strategy. They included, among others, Valladolid Tourism Master Plan, professional publications related to the project, city's marketing material related to the project, city council deliberations, official reports of the awards won by the project.

These provided the background to the study and the context that led to the project's development.

Primary sources involve five face-to-face interviews with the light designers (2) who created the project and members of the local authorities (3) who were selected because of their involvement in the different stages of the project's development - from its inception to its realisation and management (see Table 1). The aim was to collect qualitative and quantitative data from relevant stakeholders related to the chosen lighting design principles, motivations, objectives, roles envisaged for the project and achieved results. The interviews took place in May and June 2015 and each person was interviewed individually, by the author, in Spanish, a language that the researcher speaks fluently, using a semi-structured topic guide constructed from both the literature review and the analysis of the secondary sources. All interviews were formal and pre-arranged and had a duration of about an hour.

All these conversations were recorded, transcribed and then subjected to a mixture of inductive and deductive analysis, using a technique adapted from (Yin, 2003) that was already used in comparable studies (Smith and von Krogh Strand, 2011). Some of the categories were pre-conceived (derived from the literature review), but analysis procedures 
were flexible enough to allow other themes and categories to emerge from the data. Once relevant categories had been established, the principal investigator returned to the data to code it.

Table 1. The interviewees and their roles in the Ruta de los Rios de Luz project

\section{Producing a new landscape for Valladolid}

Valladolid is a Spanish city of 313,437 inhabitants located in the north of the Iberian Peninsula. Despite the fact that the city was the capital of Spain during the kingdom of Philip II in the $16^{\text {th }}$ century, Valladolid is mainly known as an industrial city. During the $19^{\text {th }}$ century the city was one of the first industrial centres of Spain, becoming the centre of the Spanish automobile industry after WWII. However, like other industrial cities in the last few decades of the $20^{\text {th }}$ century, Valladolid has experienced a period of economic depression characterized by unemployment and economic decline. In order to overcome these problems at the beginning of the new millennium, local authorities decided to implement a series of policies aimed at enhancing an urban image traditionally associated with the city's industrial past. They also sought to develop cultural tourism by leveraging the city's many heritage sites related to its period as capital of the Spanish Empire (Manero Miguel, 2011; Pastor Coello, 2014).

This transition was carried out in a series of projects. Initiated, planned, and funded by the municipal government, they primarily involved landscaping the city centre to give it a new visual narrative consistent with the city's desired image. Heritage sites that were severely rundown were restored and opened to the public, or transformed into new cultural facilities. Many areas of the historical centre were pedestrianized and cleaned up, while huge efforts were made to enhance public spaces and at the same time give them a more historical appearance. Several buildings were refaced and homogenized using traditional construction materials in order to appear like the original $16^{\text {th }}$ century buildings, while some central streets were historicized by repaving cement with traditional flagstones (Pastor Coello, 2014).

These cosmetic operations were matched by the systematic demolition of all the remaining industrial buildings, sometimes at the expense of their historical value and social significance. Perceived as a symbol of the old and undesirable industrial past, a large part of the city's 
industrial heritage was demolished and replaced with new residential areas or cultural facilities (Calderón Calderón and Pascual Ruiz-Valdepeñas, 2007).

Despite the fact that these operations partially succeeded in enhancing the status of Valladolid as a tourist destination, local authorities remained unsatisfied with the results. The dissatisfaction was mostly due to the fact that the city had become an excursion destination, with very few visitors staying in town for at least one night. According to the director of the tourist department, this was mainly due to the development of a high-speed train link that now connects the city to Madrid in just an hour.

"Initially, the easy connection with the capital was considered as an opportunity to increase the number of visitors, but it did not result in an increase of the number of overnight stays. Tourists prefer to spend a few hours in Valladolid, before going back to Madrid to enjoy its nightlife" (Interview April 2015).

The dissatisfaction with the low number of overnight stays was matched by a more general frustration related to the appearance of the city landscape that was perceived as unable to sustain the city's aspiration as a cultural tourist destination.

Despite the attempts to shape its material and symbolic value, its industrial past remained a constant presence in the city landscape. Due to the automotive industry, the city grew from 151,807 to 330,242 inhabitants between 1960 and 1981. As a result, the city experienced a quick urban expansion with the development of new working-class neighbourhoods characterized by a high number of poor quality buildings and the absence of public spaces. Yet the lack of proper planning and the failure to follow effective conservation policies during Franco's regime not only resulted in an extension of the urban area, but also deeply altered the inner city. Many parts of the historical centre were demolished to make way for new larger buildings.

The result is a profound duality of the urban landscape where historical and monumental buildings coexist with modern and large sized edifices, often of poor design and construction (Pastor Coello, 2014). Unlike other Spanish historical cities, Valladolid does not boast a wellpreserved historical centre, but has some historical buildings scattered within a modern urban framework. Crucially the absence of a well preserved old city is perceived as one of the city's main weaknesses and a competitive disadvantage compared to other nearby cities. As stated by the director of the tourist department: 
"It's hard to compete with cities like Salamanca or Burgos because they have a well preserved old city and we just have some isolated buildings." (Interview, April 2015)

A similar view was also shared by the member of Area de Presidencia that is currently in charge of the project:

“Unfortunately we don't have a real historical centre. You can find people who will tell you that the centre of Valladolid is pleasant for walking or shopping, but you will hardly find anyone who calls it beautiful." (Interview, May 2015)

These comments mirror a widespread opinion that the actual city landscape, despite all the work done, is unable to sustain the city's aspirations. As such, the local authorities decided to explore the aesthetic qualities of light to enhance the visual appearance of the city landscape and develop nocturnal tourism.

\section{The "Ruta de los Rios de Luz" project}

In 2009 the city of Valladolid received $€ 1,357,000$ from the National fund for the employment and local sustainability for the refurbishment of part of the city's lighting infrastructure. While the fund was granted to optimize energy efficiency of the city's lighting, the local authorities decided to take this opportunity to develop nocturnal tourism through the redesign of the city's monuments and heritage illumination and launched a design competition. Lighting design studio Aerolight won the competition with a project named "Ruta de los Rios de Luz".

Conceptually, the lighting design is based on the Esgueva River, an old river that used to flow through the city centre and went underground in the $19^{\text {th }}$ century.

Based on the concept of the disappeared river, the project was about creating a river of light that, according to the local authorities, aims at "showing the splendour of the Valladolid night, its history reflected through its illuminated spaces, buildings and monuments, giving value to the important and rich urban heritage" (Ayuntamiento de Valladolid, 2011 p. 155). An illuminated thematic route was designed as a type of showcase, highlighting the city's attractive elements and connecting the main landmarks with heritage sites that were illuminated through the installation of innovative, low energy lighting LEDs (Figure 1). While economic and environmental concerns were certainly an important motivation for the 
development of a new more sustainable illumination, the city's authorities main purpose was to extend the temporal distribution of tourism activities. As stated by the light designer:

“The project was born from the city's need to gain overnight stays... It was necessary to create a night-time attraction. To generate some attractions and make people stay in town" (Interview June 2015).

The aim was to extend the temporal spread of tourist activities while at the same time appeal to a wider range of visitors, not limited to those only interested in the cultural value of architectural features.

Figure 1. The light path.

Among the 35 monuments and buildings that make up the route, 16 had their existing lighting systems completely renewed, while 19 had new lighting installations placed where there were none previously. The technical quality of the installations was ensured by the use of the latest technology and low energy lighting LEDs, efficient in terms of energy, performance, colour and ease of maintenance. All the light sources were integrated within the architectural structure in order to be out of sight and not disrupt the aesthetic appearance of the buildings. They are controlled by a computer-managed system (CMS) that controls the intensity and the colour of the illumination and when to switch each individual installation on or off. Crucially, the ability of artificial light to add illusory qualities and a technological uncanny to the nocturnal experience of the city plays a key role in the project. The design aimed to enchant the nightscape and generate new visual experiences and particular atmospheres that could induce uncertainty and fascination in viewers. Yet, the operation was not only limited to the illumination of the building facades. Rather than a series of ad hoc operations, the project was characterized by a more holistic approach and a lighting master plan was developed for the entire route. Despite the fact that each building was illuminated accordingly to its particular characteristics, a common light design was established for all the operations in terms of technology used, light temperature and visual effects, according to the principle that "the techniques used should harmonize the whole spectacle" (Ayuntamiento de Valladolid, 2011 p. 155). Different light colours were used with a view to make buildings throughout the city landscape easily recognisable, mark their function and help visitor's navigation through the urban space. Greenish-blue lights were used to help tourists identify the path that connects all the lit buildings (Figure 2), following a specific colour lighting code. The illumination of religious buildings change during the year, following the liturgical colours: purple for 
Advent, Lent and liturgy for the dead ; white for Easter, Christmas, the Epiphany of our Lord, the Virgin, the Angels, Saints and Martyrs; red for Palm Sunday, Good Friday, Pentecost and the Feast of the Holy Apostles and Martyrs; and green for all other days (Figure 3). Finally, the institutional burgundy-purple colour of the city of Valladolid was used to public building like the city hall (Figure 4).

Figure 2. Light signalling elements

According to the local authorities, this solution was chosen because tourists did not perceive most of these sites as cultural facilities due to the fact that they are located in religious buildings. As noted by the light designer:

"What happens is that there are many exhibition halls and museums that are located in ancient religious buildings. We wanted to help tourists understand the use of the buildings, whether they continue to have a religious use or instead have cultural one. So we came up with a code to distinguish these two uses" (Interview, June 2015).

All along the route, the existing street lighting has been rationalized and reorganized. Superfluous light sources have been removed and the previous overlapping of different typologies of public lighting has been unified in terms of lighting technology, temperature and intensity. The result has been a reduction of the overall level of illumination in the project area.

Initially the light design proposed to act on both private and public illumination, yet local authorities refused to intervene on private and commercial illumination. As stated by the light designers "local authorities were afraid to confront the shops owners and impose the reduction of shops illumination" (Interview, June 2015). This is not an isolated case. As shown by other researches (Meier et al., 2015) the fear to losing political consensus is one of the main reasons why current lighting policies tend to focus solely on public lightning without addressing problems related to private illumination.

While this produced significant savings in both power consumption and maintenance, the reduction of the level of illumination was also motivated by aesthetic concerns. The production of a dark backdrop was designed to enhance the aesthetic qualities of the architecture and engage the eye more effectively. As stated by the light designer, one of the key elements of the set design was "to give a visual coherence to street lighting and reduce the intensity of the light sources in order to avoid competition with the heritage illumination. 
When you reduce the overall level of lighting, the illuminated features are better perceived" (Interview, June 2015).

\section{Figure 3. Church of San Benito}

Rather than a simple functional and pragmatic cog, the illumination was designed with the aim of producing a new visual order, to give the city a more coherent visual narrative and render the space more conducive for tourism. As noted by Edensor and Lorimer (2015) "in the darkness, small patches of light in an otherwise dark landscape, or contrastingly brightly lit areas, usually serve to focus vision far more acutely than in the daylight where a landscape comprised of textural detail is liable to draw and distract the eye away from targeted attention" (p.4).

Lighting effects have been designed to work towards a greater sense of navigation for visitors at night and a greater appreciation of the thematic elements of the city and its features highlighted and facilitated via the spectacle of calculated illumination. As noted by the light designer, the project:

"is a construction of the nocturnal landscape and is a scenic construction... All we did was to imagine how we would like this route to be seen and shape it through lights" (Interview, June, 2015).

The different lights projected onto the cityscape aim to become a coherent, hegemonic network of signifiers that codifies new landscapes of hierarchical selectiveness. Acting on the intensity, typology and disposition of the light source, the project carefully attempts to produce a series of interplay of light and shadow that simultaneously highlight and erase some features of the urban landscape. Essential points are highlighted while others not worthy are shrouded in darkness, producing a temporal aesthetization of the urban landscape. As stated by the member of the Area of Presidencia in charge of the project:

"Illumination allows you to highlight what you want to show and hide what you don't want to show. At night Valladolid is beautiful because you don't see all these ugly buildings" (Interviews, May, 2015).

Crucially this process, that Ebbensgaard (2015a) labelled "luminous reduction", should not be conceptualized as a simple attempt to make the nightscape more pleasing to look at, but reflects instead the increasingly political nature of urban illumination (Deleuil, 2009). In recent years, local authorities have been using urban illumination as a tool to build a sort of ideal nocturnal landscape, produced by the careful selection of specific symbols and 
buildings, which aim to communicate a specific and edited urban image (Mallet, 2010). Interestingly, in the case of Valladolid, while the light designer was in charge of developing the light concept and its rationale, the selection of the illuminated buildings was made by the local authorities. As stated by the director of the Area de Presidencia:

"We discuss with the light designer which monuments should be illuminated, but we have the last word" (Interview, 2015).

According to them, the criterion applied to select which buildings to illuminate was their historical value. However the project reflects a very specific idea of Valladolid's history. Almost all of the illuminated buildings are heritage sites related to Valladolid's period as capital of the Spanish Empire or new cultural facilities like the Millennium Dome (Figure 5), while the existing industrial heritage has not been included in the project, despite the fact that some sites have been declared national heritage. The result is an edited landscape that is coherent with the narrative that the local authorities are trying to portray: Valladolid as both an historical and creative city while its industrial past is symbolically, but also visually, left in the dark. This political dimension is explicitly recognized by the lighting designer:

"Illumination has become a tool for marketing; when you work on the illumination of the nocturnal landscape, it is important to align it with the urban project" (Interview, May 2015)

Figure 4. The City Hall

Crucially, illumination is not simply designed to beautify the aesthetic appearance of the city's landscape but also to reproduce a seductive logic that exerts power through ambient qualities (Allen, 2006). Light has been treated as true scenic material that, though altering the aesthetic appearance of material surfaces, aims to influence tourist gaze and action in order to produce an attractive, but at the same time highly monitored, experience of the city. The light designer unambiguously acknowledges the use of lighting effects to direct the visitor's gaze towards particular features when he states:

"We work on what is seen walking through the route... we work this visual landscape searching to focus the attention to certain areas and reduce it to others." (Interview, June 2015)

Regarding the achieved results, the stakeholders interviewed seemed delighted with the initial outcomes. According to the local authorities, the number of overnight stays in the city has increased by $12 \%$ since the launch of the project in 2011 and data from the Tourism Department shows that more than 40,000 visitors joined the guided tours that are organized 
during the weekends. Yet as far as the development of more sustainable lighting strategies is concerned, opinions seems to diverge. The use of more recent lighting technology has resulted in significant energy savings and cost reduction. With the illumination of 19 new sites, the overall energy consumption has been reduced by $45 \%$, and the current electricity bills related to the project are entirely covered by the revenue derived from ticket sales for the guided tours (Ayuntamiento de Valladolid, 2011). These results have been mostly achieved thanks to the use of more modern lighting LEDs that require lower levels of energy to create the same level of illumination. Further savings have been achieved through the refurbishment of part of the existing street lighting that was rationalized both in terms of design and placement. At the same time, the reduction of the overall level of street lighting illumination has also helped lowering the intensity of heritage lighting thanks to a decreased visual competition between the two types of illumination, further reducing light pollution and energy consumption.

Local authorities have deemed these results as remarkable and the project has been communicated by the city as a benchmarks in term of a sustainable lighting strategy (Ayuntamiento de Valladolid, 2011)

The opinions of light designer opinions are more cautious. While concerns about energy consumption and light pollution have been considered and integrated in the lighting design, the project is too limited in scale and scope to successfully address these issues at urban level. "The project is not a Lighting Master Plan. It is a small project with a specific purpose and a relatively small area of interest. It is not designed to address questions of energy consumption and light pollution at urban level” (Interview, 2015). Indeed recent studies have pointed out the need to address both energy consumption and light pollution through a lighting plan designed at urban or even regional level (Azam, Le Viol, Julien, Bas and Kerbiriou, 2016; Deleuil, 2009; Kyba et al., 2014).

Yet these remarks have not been considered by the city authorities and to date the city does not possess a lighting plan, which leaves questions relating to the sustainability of the city's lighting systems still unaddressed.

At the same time, despite the fact that according to local authorities the light walk has improved both residents and tourists experience of Valladolid at night the lighting design and rationale raise questions about the effects that these spectacular forms of illumination, mainly designed to attract tourists, could have on the more everyday practices and experiences of the nocturnal city. 
The growing number of visits seems to confirm the capacity of artistic forms of illumination to work towards a greater sense of navigation for visitors at night and a greater appreciation of the thematic elements of the city and its elements - highlighted and facilitated via the spectacle of calculated illumination (Giordano and Ong, 2017). Yet, recent studies have highlighted, not only how illumination is experienced and consumed in multiple and contextual ways (Ebbensgaard, 2015; Giordano and Crozat, 2017) but also the negative consequences that promoting places through the lens of tourist gazing could potentially have on the urbanity of the city (Urry and Larsen, 2011). Despite the fact that the project claims to add value to spaces, enhancing and facilitating the experience of Valladolid at night for both tourists and residents, lighting operations appear to have been guided mainly by technical and aesthetic concerns, while the experiential dimensions of lights seem to have been less scrutinized and problematized. More generally the rationale of the project seems to associate an aesthetization of the visual appearance of material surfaces with an increased liveability and the creation of value for people.

Crucially this conceptualization of light is not a peculiarity of Valladolid's design. A series of studies on lighting projects have instead highlighted how this focus on the creation of surface aesthetics is a broader trend in light design (Hernandez, 2010; Mallet 2010, 2011). However, recent works on the sensory every-night experiences of the changed aesthetics of illuminated spaces have shown how the simple alteration of the aesthetic appearance of material surfaces does not necessarily improve the every-night experience of the urban spaces, but could instead have counterproductive effects (Ebbensgaard, 2015a). While, according to the stakeholders, the project has successfully improved the experience of Valladolid at night for both citizens and tourists, until now no study has been developed on the experience of Valladolid's lightscapes, leaving a lack of knowledge on what kind of urbanity and everynight experience the project produces.

Figure 5. The Millennium Dome

\section{Conclusion}


Over the past few years the urban night has assumed a growing importance for the tourism and hospitality sector (Evans, 2012). In this context, the development of a vibrant nightlife has become a key element of tourism competitiveness. However, while this opportunity has been taken up by many national capital cities as well as some regional and provincial cultural capitals, most of the cities do not possess a critical mass of cultural assets able to attract international or national nightlife nor party-focused tourism. As such, a large number of medium and small-sized cities have tried to develop alternative strategies to encourage tourists to extend their stays. In this context, the development of spectacular forms of illumination has become a strategy chosen by a growing number of cities and a vital part of regeneration strategy and place promotion. They can provide a valid alternative to the traditional night-life of entertainment areas while contributing to extending the geographical and temporal distribution of tourism activities within the city.

At the same time, the use of illumination in cultural-led regeneration strategies is often accompanied by increasing concerns to develop sustainable lighting with more innovative design serving as a catalyst to create a new commitment towards the adoption of more innovative lighting technologies and design. As in the case of Valladolid, the project "Ruta de los Rios de Luz" has not only helped producing electricity savings and reducing light pollution, but has also served as the catalyst for a broader revision of Valladolid's lighting strategy. The results have convinced local authorities to further invest in the development of a more sustainable illumination. The city has joined an international association of local authorities and light designers called LUCI (Lighting Urban Community International) and signed the association's charter which advocates the promotion and development of a culture of sustainability in lighting. As a result, over the past three years, a number of actions have been carried out on everyday lighting across the city through the installation of new LED lighting and new smart lighting systems. Yet issues relating to the city's lighting system sustainability remain unaddressed. Having only focused on the development of Valladolid's nocturnal tourism the project is too limited in scale and scope to successfully address issues such as lighting pollution and energy consumption at urban level, highlighting the need to integrate these types of projects into the framework of a Lighting Master Plan for the whole city. Furthermore, while the project seems to have been successful from a strictly tourist perspective, questions remain about the effect that this alteration of the visual appearance of space might have on the urbanity of the nocturnal city. The case of Valladolid shows how both local authorities and light designers tend to conceptualize light as a scenic material that could be employed to unify the narrative of the urban space and to render the space more 
conducive to visiting and navigation. This operation is neither neutral nor objective, however, but instead highly political. Through the careful orchestration of the lighting effects, the project attempts to produce a more seductive spatial arrangement that is designed to exercise ambient power in order to influence how the nocturnal city is experienced by visitors. At the same time, despite claims that it enhances the liveability of the city at night, light design is mainly conceived in terms of aesthetical surfaces while the experimental dimension of light has been sparingly integrated in design decisions. To date, no studies have investigated the experience of these aestheticized spaces, leaving a lack of knowledge on the kinds of experiences they produce. While spectacular forms of illumination seems to offer in terms of tourist development and environment sustainability, these is the need to integrate the aesthetic and technical aspects of light with a more critical examination of the performative effects that spectacular forms of illumination may have on the every-night experience of the city.

\section{References}

Agence de développement touristique de la France (ATOUT) (2012). Concevoir la lumière comme un levier de développement touristique. Paris. Editions ATOUT.

Allen, J. (2006). Ambient Power: Berlin's Potsdamer Platz and the Seductive Logic of Public Spaces. Urban Studies, 43(2), 441-455.

Alves, T. (2007). Art, Light and Landscape New Agendas for Urban Development. European Planning Studies, 15(9), 1247-60.

Ayuntamiento de Valladolid. (2011). Valladolid. Rios de Luz.

Azam, C., Le Viol, I., Julien, J.-F., Bas, Y., Kerbiriou, C. (2016). Disentangling the relative effect of light pollution, impervious surfaces and intensive agriculture on bat activity with a national-scale monitoring program. Landscape Ecology. DOI: 10.1007/s10980016-0417-3

Beriatos, E., \& Gospodini, A. (2004). "Glocalising" urban landscapes: Athens and the 2004 Olympics. Cities, 21, 187-202.

Brons, J., Bullough, J., \& Rea, M. (2008). Outdoor site-lighting performance: comprehensive and quantitative framework for assessing light pollution. Lighting Research \& Technology, 40(3), 201-224.

Bulkeley, H., Broto, V.C., \& Edwards G. (2012). Bringing climate change to the city: towards low carbon urbanism?. Local Environment, 17, 545-551.

Calderón Calderón, B. \& Pascual Ruiz-Valdepeñas, H. (2007). El lugar del patrimonio industrial en los procesos de transformación urbana: de la ruina a la explotación de las reliquias fabriles en Valladolid. Ería, 72, 55-73.

Challéat, S. (2010). "Sauver la nuit » : empreinte lumineuse, urbanisme et gouvernance des territoires. PhD Thesis in Geography, University of Dijon.

Deleuil, J.M. \& Toussaint, J.-Y. (2000). De la sécurité à la publicité, l'art d'éclairer la ville. Les Annales de la Recherche Urbaine, 87, 52-58. 
Deleuil, J.-M. (2009). Eclairer la ville autrement. Innovations et expérimentations en éclairage public. Lyon: Presses Polytechnique et Universitaires Romandes

Dicks, B. (2003). Culture on Display: the Production of Contemporary Visitability. London: Open University Press.

Ebbensgaard, C.L. (2015a). Illuminights A Sensory Study of Illuminated Urban Environments in Copenhagen. Space and Culture, 18, 112-131.

Ebbensgaard, C. L. (2015b). Urban lighting, light pollution and society. European Planning Studies, 23, 1437-1440.

Edensor, T. (2001). Performing tourism, staging tourism (Re)producing tourist space and practice. Tourist Studies, 1, 59-81.

Edensor, T. (2012) Illuminated atmospheres: anticipating and reproducing the flow of affective experience in Blackpool. Environment and Planning D: Society and Space, 30(6), 1103-1122.

Edensor, T. (2015a). The Gloomy City: Rethinking the Relationship between Light and Dark. Urban Studies, 52(3), 422-438.

Edensor, T. (2015b). Light Design and Atmosphere, Visual Communication, 14(3), 331-350.

Edensor, T. \& Lorimer, H. (2015). "Landscapism" at the Speed of Light: darkness and illumination in motion. Geografiska Annaler: Series B, Human Geography, 97 (1), 116.

Edensor, T., \& Millington, S. (2012). Blackpool Illuminations: Revaluing local cultural production, situated creativity and working-class values. International Journal of Cultural Policy, 19, 145-161.

Evans, G. (2012). Hold back the night: Nuit Blanche and all-night events in capital cities. Current Issues in Tourism, 15(1-2), 35-49.

Fiori, S. (2000). Réinvestir l'espace nocturne : les concepteurs lumière. Les Annales de la Recherche Urbaine, 87, 73-80.

Fouquet, R. (2006). Seven centuries of energy services: the price and use of light in the United Kingdom (1300-2000). The Energy Journal, 27, 139-177.

Freitag, T. (1994). Enclave Tourist Development: For Whom the Benefits Roll?. Annals of Tourism Research, 21, 538-54.

Giordano, E. \& Ong, C. E. (2017). Light festivals, policy mobilities and urban tourism.

Tourism Geographies, doi.org/10.1080/14616688.2017.1300936

Giordano, E. \& Crozat, D. (2017). Expérience visuelle et performance de la mise en lumière du patrimoine : Aller au-delà de la séduction. Annales de Géographie,714 (2), 195-215.

Gospodini, A. (2001). Urban Design, Urban Space Morphology, Urban Tourism: An Emerging New Paradigm Concerning Their Relationship. European Planning Studies, 9(7), 925-34.

Gospodini, A. (2002). European Cities in Competition and the New "Uses" of Urban Design. Journal of Urban Design, 7, 59-73.

Gospodini, A. (2004). Urban morphology and place identity in European cities: built heritage and innovative design. Journal of Urban Design, 9, 225-248.

Gottdiener, M. (1997). The Theming of America. Oxford:Westview Press.

Gravari-Barbas, M. (1998). Belle, propre, festive et sécurisante : l'esthétique de la ville touristique. Norois, 178, 175-193.

Guo, Q., Lin, M., Meng, J., \& Zhao, J. (2011). The Development of Urban Night Tourism based on the Nightscape Lighting Projects - A Case Study of Guangzhou. Energy Procedia, 5, 477-481.

Hernandez Gonzalez, E. (2010). Comment l'illumination nocturne est devenue une politique urbaine : la circulation de modèles d'aménagement de Lyon (France) à Puebla, Morelia et San Luis Potosì (Mexique). PhD thesis. Université Paris-Est. 
Jönsson, E. (2011). Economy of Fascination: Dubai and Las Vegas as Themed Urban

Landscapes. European Planning Studies, 19, 551-553.

Julier G. (2005). Urban Designscapes and the Production of Aesthetic Consent, Urban Studies, 42 (5/6), 869-887.

Köhler, D. (2015). The Lighting Master Plan as an Instrument for Municipalities?. In J. Meier, U. Hasenöhrl, K. Krause \& M. Pottharst (Eds.), Urban Lighting, Light Pollution and Society (pp. 141-158). New York: Routledge.

Kyba, M., Hänel, A., \& Hölker, F. (2014). Redefining efficiency for outdoor lighting. Energy \& Environmental Science, 7, 1806-1809.

Longcore, T. \& Rich, C. (2004). Ecological Light Pollution. Frontiers in Ecology and the Environment, 2(4),191-98.

LUCI (2015). Lighting Heritage Sites. Cities and Lighting, 2, 14-27

Lukas, S. A. (2007). The Themed Space: Locating Culture, Nation and Self. New York: Lexington Books.

Madanipour, A. (2006). Roles and Challenges of Urban Design. Journal of Urban Design, $11,173-193$.

Mallet, S. (2010). Exposer Les Espace Référents D'une Politique Urbaine : Le Cas de Mises en Lumière à Bordeaux. Lieux Communs, 13, 37-53.

Mallet, S. (2011). Paysage Lumière et environnement urbain nocturne, Espaces et sociétés, $145,35-52$.

Manero Miguel, F. (2011). En defensa de la identidad difuminada: estrategias de creatividad y promoción turística en ciudades medias. El caso de Castilla y León. Investigaciones Geográficas, 56, 31-47.

McNeill, D. (2000) McGuggenisation? National identity and globalisation in the Basque Country. Political Geography, 19, 473-494.

Meier, J., Hasenöhrl, U., Krause, K. \& Pottharst, M. (Eds.) (2015), Urban Lighting, Light Pollution and Society. New York: Routledge.

Meier, J., Pottharst, M., Krause K., \& Hasenöhrl, U. (2015). The new visibility of lighting. In J. Meier, U. Hasenöhrl, K. Krause \& M. Pottharst(Eds.), Urban Lighting, Light Pollution and Society (pp. 1-5). New York: Routledge

Morris, N. (2011). Night walking: darkness and sensory perception in a night-time landscape installation. Cultural Geographies, 18(3), 315-342.

Narboni, R. (2004). Lighting the Landscape. Basel, Boston: Birkhäuser Architecture

Narboni, R. (2012). Les éclairages des villes : vers un urbanisme nocturne. Paris : Collection Archigraphy. Gollion

Ockman, J. (2004) New politics of the spectacle: 'Bilbao' and the global imagination. In D. Lasansky and B. McClaren (Eds.), Architecture and Tourism: Perception, Performance and Place (pp. 227-240). Oxford: Berg.

Pastor Coello, M. (2014). Del deterioro del patrimonio a su puesta en valor e inclusión en la planificación turística: El caso de Valladolid. Cuadernos de Turismo, 34, 213-232

Peck, J. (2012). Austerity urbanism. City, 16, 626-655.

Plaza, B. (2000). Guggenheim museum's effectiveness to attract tourism. Annals of Tourism Research, 27, 1055-1058

Plaza B., Tironi, M. and Haarich S. (2009) Bilbao's art scene and the 'Guggenheim effect' revisited. European Planning Studies, 17(11): 1711-1729.

Plaza, B., \& Haarich, S.N. (2015). The Guggenheim Museum Bilbao: Between Regional Embeddedness and Global Networking. European Planning Studies, 23, 1456-1475.

Rodrigues, A.L.O., Rodrigues, A., \& Peroff, D.M. (2015). The Sky and Sustainable Tourism Development: A Case Study of a Dark Sky Reserve Implementation in Alqueva. International Journal of Tourism Research, 17, 292-302. 
Rojek, C. (1995). Decentring Leisure. London: Sage.

Schulte-Römer, N. (2011), "Light for remaking cities: trends and reflections on urban design", in Professional Lighting Design 3rd Global Lighting Design Convention, Conference Proceedings 60 60-63, http://www.wzb.eu/sites/default/u149/proceedings_nsr.pdf

Shaw, R. (2014). Streetlighting in England and Wales: new technologies and uncertainty in the assemblage of streetlighting infrastructure. Environment and Planning A, 46, 2228 $-2242$

Smith, A., \& von Krogh Strand, I. 2011. Oslo's new Opera House: Cultural flagship, regeneration tool or destination icon?, European Urban and Regional Studies 18, 93110.

Stephenson, M.L. (2014). Tourism, development and "destination Dubai": cultural dilemmas and future challenges. Current Issues in Tourism 17, 723-738.

Stevens, Q., \& Dovey, K. (2004). Appropriating the spectacle: play and politics in a leisure landscape. Journal of Urban Design, 9(3), 351-365

Urry, J. \& Larsen, J. (2011). The Tourist Gaze 3.0. London: Sage.

Van der Hoven, F.D., Smit, M.G.J. \& Van der Spek, S.C. (2008). Street-level desires. Discovering the city on foot. Delft: TU Delft.

Van Santen, C. (2006). Light Zone City. Light Planning in the Urban Context. Basel, Boston and Berlin: Birkhauser.

Yin, R. (2003) Case Study Research: Design and Methods (3rd ed.). London: Sage. 